Article

\title{
Improved Isolation Procedures for Okadaic Acid Group Toxins from Shellfish (Mytilus edulis) and Microalgae (Prorocentrum lima)
}

\author{
Jane Kilcoyne ${ }^{1, *(\mathbb{D}}$, Stephen Burrell ${ }^{1}$, Cíara Nulty ${ }^{1}$, Rafael Salas ${ }^{1}$, Elliott J. Wright ${ }^{2}$, \\ Isabelle Rajotte ${ }^{2}$ and Christopher O. Miles ${ }^{2}$ (i) \\ 1 Marine Institute, Rinville, Oranmore, Co. Galway H91 R673, Ireland; stephen.burrell@marine.ie (S.B.); \\ ciara.nulty@marine.ie (C.N.); rafael.salas@marine.ie (R.S.) \\ 2 Biotoxin Metrology, National Research Council Canada, Halifax, NS B3H 3Z1, Canada; \\ elliott.wright@nrc-cnrc.gc.ca (E.J.W.); isabelle.rajotte@nrc.ca (I.R.); christopher.miles@nrc-cnrc.gc.ca (C.O.M.) \\ * Correspondence: jane.kilcoyne@marine.ie; Tel.: +353-91387200
}

Received: 16 November 2020; Accepted: 14 December 2020; Published: 16 December 2020

\begin{abstract}
Okadaic acid (OA) group toxins may accumulate in shellfish and can result in diarrhetic shellfish poisoning when consumed by humans, and are therefore regulated. Purified toxins are required for the production of certified reference materials used to accurately quantitate toxin levels in shellfish and water samples, and for other research purposes. An improved procedure was developed for the isolation of dinophysistoxin 2 (DTX2) from shellfish (M. edulis), reducing the number of purification steps from eight to five, thereby increasing recoveries to $\sim 68 \%$, compared to $\sim 40 \%$ in a previously reported method, and a purity of $>95 \%$. Cell densities and toxin production were monitored in cultures of Prorocentrum lima, that produced OA, DTX1, and their esters, over $~ 1.5$ years with maximum cell densities of $\sim 70,000$ cells $\mathrm{mL}^{-1}$ observed. Toxin accumulation progressively increased over the study period, to $\sim 0.7$ and $2.1 \mathrm{mg} \mathrm{L}^{-1}$ of OA and DTX1 (including their esters), respectively, providing information on appropriate harvesting times. A procedure for the purification of OA and DTX1 from the harvested biomass was developed employing four purification steps, with recoveries of $\sim 76 \%$ and purities of $>95 \%$ being achieved. Purities were confirmed by LC-HRMS, LC-UV, and NMR spectroscopy. Additional stability observations led to a better understanding of the chemistry of these toxins.
\end{abstract}

Keywords: OA group toxins; DSP; purification; shellfish; Prorocentrum lima; marine biotoxins; LC-MS; NMR

\section{Introduction}

Okadaic acid (OA) group toxins (Figure 1) are lipophilic polyether toxins produced by the genera Prorocentrum [1,2] and Dinophysis [3,4] that can lead to diarrhetic shellfish poisoning (DSP) events. The first poisoning incident associated with this toxin group occurred in Japan in 1976, following the consumption of mussels [5]. The OA group is comprised principally of okadaic acid (OA), dinophysistoxin 1 (DTX1), dinophysistoxin 2 (DTX2), and their esters [4]. The esters can be produced by the microalgae (Dinophysis and Prorocentrum spp.) [6-9], or by the shellfish via esterification of the toxins [10].

The EU regulatory limit is set at $160 \mu \mathrm{g} \mathrm{kg}{ }^{-1}$ for OA, DTX1, DTX2, and their esters [11], with the EU regulatory method of analysis being LC-MS/MS [12]. The current toxic equivalent factors (TEFs) applied in the regulation (OA $=1$, DTX1 $=1$, DTX2 $=0.6)$ are based on intraperitoneal studies; however, a recent mouse oral study assessing toxicity suggested TEFs of OA $=1$, DTX1 $=1.5$, 
DTX2 $=0.3$ [13]. Another study using the in vitro neuro-2a bioassay found that DTX1 is more potent than OA, while DTX2 is less potent [14].

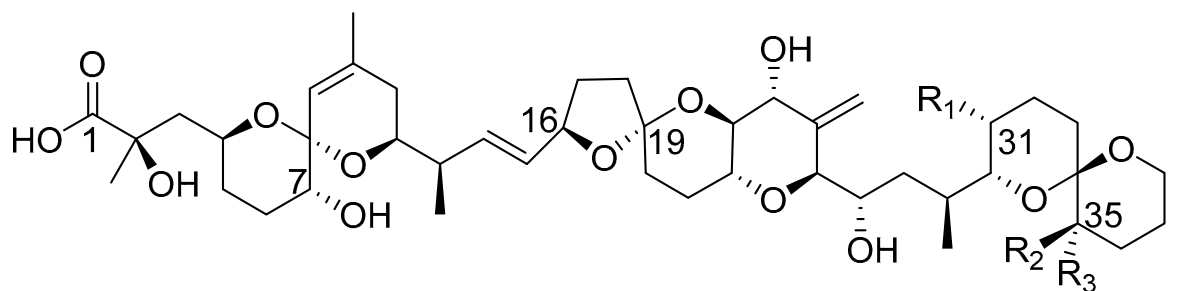

\begin{tabular}{cccc}
\hline Toxin & $\mathbf{R}_{\mathbf{1}}$ & $\mathbf{R}_{\mathbf{2}}$ & $\mathbf{R}_{\mathbf{3}}$ \\
\hline $\mathrm{OA}$ & $\mathrm{CH}_{3}$ & $\mathrm{H}$ & $\mathrm{H}$ \\
DTX1 & $\mathrm{CH}_{3}$ & $\mathrm{CH}_{3}$ & $\mathrm{H}$ \\
DTX2 & $\mathrm{H}$ & $\mathrm{H}$ & $\mathrm{CH}_{3}$ \\
\hline
\end{tabular}

Figure 1. Structures of major okadaic acid (OA) group toxins.

Detection of OA group toxins in shellfish samples has resulted in significant shellfish farm closures worldwide [4,15]. In Ireland, OA group toxins are detected in shellfish annually, predominantly arising from blooms of Dinophysis acuta and Dinophysis acuminata, leading to regular shellfish harvesting restrictions, particularly during the summer months [16].

OA group toxins are serine/threonine protein phosphatase inhibitors; however, the observed harmful effects of these toxins (not relating to DSP) cannot be explained by protein phosphatase inhibition alone, and therefore more research into the mechanism of action is warranted $[17,18]$. As serine/threonine protein phosphatases play an important role in cellular processes, OA is used as a tool in the study of various human diseases that are linked to their dysregulation (e.g., Alzheimer's disease) $[19,20]$.

The availability of highly pure toxin for the production of certified reference materials (CRMs) is essential to ensure that monitoring programs can accurately quantitate levels of these toxins in shellfish and water samples, and for ensuring reliable quantitative toxicological evaluations. Pure compounds are further required for developing new analytical methods, and for use in other areas of research (e.g., pharmacology, the development of biosensors, etc.). Efficient isolation procedures are therefore necessary to provide these compounds cost-effectively and in sufficient purity and quantity to permit toxicological studies and method development.

Many Prorocentrum spp. produce OA, DTX1, and their diol esters [21], while Dinophysis spp. can produce OA, DTX1, DTX2, their diol esters, and pectenotoxins (PTXs) [4]. The toxin profiles can vary between location and strain. A recent study reported the full metabolomic profile of Galacian strains of D. acuta and D. acuminata by LC-MS/MS. The complex and diverse chemical profiles differed significantly between species, feeding regimes, and prey organisms [22].

Prorocentrum spp. are relatively straightforward to culture and can produce relatively high amounts of toxin per cell (pg cell ${ }^{-1}$ ). The Dinophysis spp., however, are much more difficult to grow because they require a ciliate to feed on, which in turn needs to be fed with a cryptophyte [23]. OA, DTX1, and PTX2 were isolated via large-scale cultivation of D. acuminata [24]. However, to date, there are no reports of DTX2 purification from Dinophysis culture biomass. Sources of DTX2 for purification have come from shellfish (Mytilus edulis) [25-27], and in situ harvesting of a D. acuta bloom [28]. OA and DTX2 have been synthesised, but synthesis requires multiple steps, with low yields $(<3 \%)[29,30]$.

The methods reported to date describe up to eight- and six-step procedures for the purification of OA/DTXs from shellfish and microalgae, respectively [26,27,31]. In this paper, we describe efforts made, as part of the MARBioFEED project [32], to enhance the purification methods for the isolation of these toxins and to further assess toxin stability. 


\section{Results and Discussion}

\subsection{Isolation of DTX2 from Shellfish}

A method published in 2016 describes an eight-step procedure for purification of DTX2 from shellfish, with recoveries of $\sim 40 \%$ [26]. Once extracted, the sample underwent a partitioning between water and EtOAc, followed by hydrolysis (to convert the esterified forms back into DTX2), and a second partitioning between hexane and aqueous $\mathrm{MeOH}$. The sample was further purified using column chromatography on silica gel, LH-20, and phenyl-hexyl phases before using semi-preparative reverse-phase HPLC with a neutral mobile phase (Figure 2A).

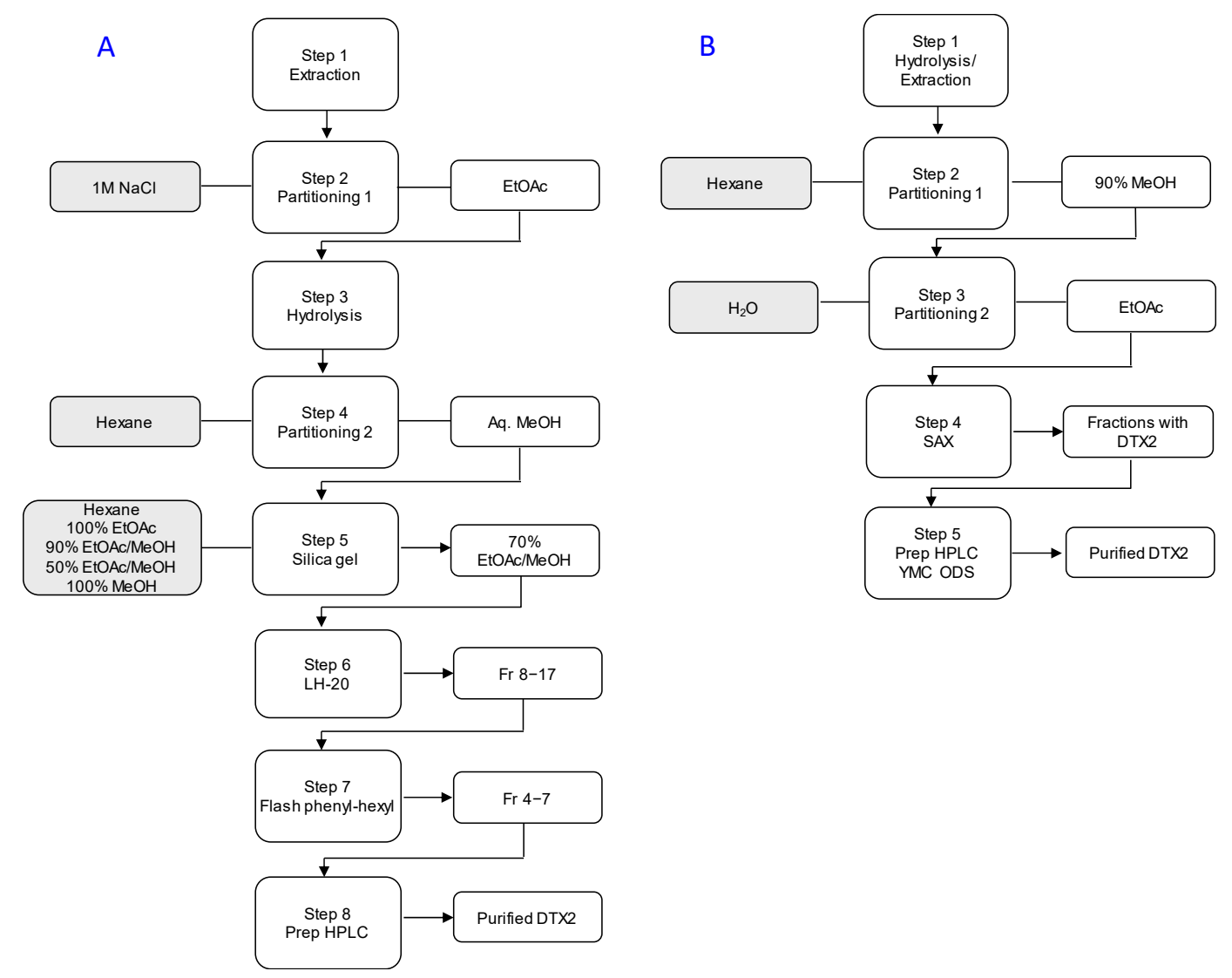

Figure 2. Two methods for isolation of dinophysistoxin-2 (DTX2) from shellfish: (A) the procedure of Beach et al. [26], and; (B) the newly-developed improved method.

Efforts were made to improve procedural efficiencies and yields. The shellfish used in this study were the same as those used in the Beach et al. study [26]. The hepatopancreas (in which the toxins are concentrated) was dissected, homogenised, and freeze dried. LC-HRMS analysis of a hydrolysed extract showed that a significant proportion ( $75 \%)$ of the total DTX2 present in the sample was in the esterified form. The initial extraction step was combined with base-hydrolysis to convert the DTX2 esters back into the parent compound. This led to a more efficient extraction and eliminated one step from the previously reported procedure [26]. The first two partitioning steps in the method reported by Beach et al. [26] were performed in reverse order, which also reduced the number of evaporation steps required. Following the partitioning between hexane and aqueous $\mathrm{MeOH}$, the sample was evaporated and taken up in $\mathrm{MeOH}$, resulting in the precipitation of salts, which were removed by filtration. The sample was then evaporated and partitioned between water and EtOAc. This had the effect of enhancing the clean-up (via reduction in the sample mass) by $81 \%$ (five-fold) compared to 
the previously reported procedure [26]. A similar enhanced clean-up was also obtained in separate azaspiracid (AZA) isolations where the first two partitioning steps [33] were reversed (data not shown).

Method development trials were then performed comparing alumina (using the method described in Section 3.4) and strong anion exchange (SAX) chromatography. A significantly improved clean-up was achieved using SAX chromatography (Figure S1), and a method was developed such that a clean-up of $\sim 94 \%$ was achieved with a recovery of $>95 \%$. Prior to loading the sample onto the SAX stationary phase, the sample was taken up in 3:7 MeOH- $\mathrm{H}_{2} \mathrm{O}$, to which ammonium bicarbonate was added. The ammonium bicarbonate enabled complete dissolution of the sample. The toxin was eluted using a pH-gradient (from pH 3.0 to 2.6, in steps of $0.2 \mathrm{pH}$ units) of acidic water. The sample was then sufficiently pure for semi-preparative HPLC (Figure S1B).

The enhanced DTX2 clean up achieved in this study, by reversing the first two partitioning steps and adding SAX chromatography, enabled the silica gel, LH-20, and flash phenyl-hexyl chromatographic steps reported in the Beach et al. [26] procedure to be eliminated (Figure 2B and Table 1). The Beach et al. [26] method employed a neutral mobile phase for the final purification step (semi-preparative HPLC). Using such a mobile phase gives rise to poorly shaped peaks and separation from other sample contaminants. The method was amended in the present study to use an acidic ( $\mathrm{pH} 3.3$ ) mobile phase, which resulted in good peak shape and sufficient separation of the DTX2 from other sample impurities.

Table 1. Batch summary for isolation of DTX2 from shellfish, as assessed by LC-HRMS (Section 3.5.1).

\begin{tabular}{|c|c|c|c|c|c|}
\hline & Weight (mg) & $\begin{array}{c}\text { Clean-up } \\
\left(100 \times\left(W_{i}-W_{f}\right) / W_{i}\right)(\%)\end{array}$ & DTX2 (mg) & Step Recovery (\%) & Purity (\%) \\
\hline Wet weight (g) & 422,000 & & ^ 10.7 & & \\
\hline Dry weight (g) & 118,000 & & $\wedge 10.7$ & & \\
\hline Step 1 (hydrolysis/extraction) & 53,000 & & 10.5 & & 0.02 \\
\hline Step 2 (hexane partitioning) & 28,000 & 47.2 & 10.3 & 98.1 & 0.04 \\
\hline Step 3 (EtOAc partitioning) & 3300 & 88.2 & 9.9 & 96.1 & 0.30 \\
\hline Step 4 (SAX chromatography) & 200 & 95.6 & 8.4 & 84.8 & 4.20 \\
\hline Step 5 (semi-prep HPLC) & & & 7.3 & 86.9 & $* 96.7$ \\
\hline$\%$ Recovery & & & 68.2 & & \\
\hline
\end{tabular}

The organic solvent was evaporated from the combined DTX2 fractions and the $\mathrm{pH}$ of the sample was adjusted to 7 using $\mathrm{NaOH}$, to reduce the effects of acid instability (see below). The DTX2 was recovered on solid-phase extraction (SPE) cartridges to remove any buffers and salts in the sample but also to reduce the water content in, and volume of, the DTX2 fractions prior to evaporation. This SPE recovery resulted in very little loss of toxin, with recoveries of $>98 \%$ being achieved.

The purification of DTX2 is complicated by the fact that it can form an isomeric degradation product (19-epi-DTX2). The 19-epimer elutes at the same time as OA (using the methods described in this study), and hence it is desirable that the levels of this epimer remain as low as possible, so as not to interfere with the analysis of OA when a mixed CRM solution is prepared. Purity analysis of DTX2 by LC-HRMS and LC-UV indicated purities were 95\% (Tables 1 and 2; Figures S2-S4). The 19-epimer of DTX2 was present at $\sim 2.4 \%$ (Table 2; Figures S2 and S3), so a preliminary investigation of the kinetics of the 19-epimerisation reaction was conducted using LC-MS/MS with a neutral mobile phase to minimise potential on-column isomerisation reactions. This showed that epimerisation was not measurable in neutral $\mathrm{MeOH}$ at $10{ }^{\circ} \mathrm{C}$ overnight, whereas epimerisation followed pseudo first-order kinetics with a half-life of $2.3 \mathrm{~h}$ in $\mathrm{MeOH}$ containing $1 \% v / v$ formic acid at $10^{\circ} \mathrm{C}$ (Figure S5). Extrapolation of the kinetic data indicated that at equilibrium, 2-3\% of the DTX2 would be present in the form of its 19-epimer under these conditions, and given their structural similarities, OA and DTX1 are likely to be similarly susceptible to acid-catalysed epimerisation. In addition, two earlier-eluting peaks, with $\mathrm{m} / \mathrm{z}$ consistent with DTX2 $+\mathrm{H}_{2} \mathrm{O}$, were also detected that together comprised $\sim 0.9 \%$ (Table 2 and Figures S2 and S3) by LC-HRMS. Similarly, DTX2 + MeOH isomers and very low levels of DTX2 $+\mathrm{CD}_{3} \mathrm{OH}$ isomers (which must have been produced during NMR analysis) were subsequently detected by LC-HRMS. 
These observations are consistent with the mechanisms shown in Figure 3, the rate and extent of which will vary with solvent, $\mathrm{pH}$, temperature and length of storage. Other ketal centres in DTX2 probably also undergo epimerisation, given the detection of at least four $\mathrm{MeOH}$ derivatives after storage and shipment of the sample, but these other reactions are probably slower, given that only two peaks containing $\mathrm{CD}_{3} \mathrm{OH}$-derivatives were observed after ${ }^{1} \mathrm{H}$ NMR analysis (Figures S6-S10). In a previous study, isomerization of AZA1 was observed during NMR analysis in $\mathrm{CD}_{3} \mathrm{OD}$ but appeared to cease upon addition of $0.1 \% v / v \mathrm{~d} 5$ pyridine [34], suggesting that such isomerisations are also acid-catalysed.

Table 2. LC-HRMS (Section 3.5.2) analysis of purified DTX2 (after NMR analysis, Figure S3).

\begin{tabular}{cccccrr}
\hline Toxin & \multicolumn{2}{c}{$\mathbf{O A}+\mathbf{H}_{\mathbf{2}} \mathbf{O}$} & OA + MeOH & DTX2 + CD ${ }_{3}$ OH & 19-epi-DTX2 & DTX2 \\
\hline Accurate mass $(m / z)$ & 821.4700 & 821.4716 & 835.4857 & 838.5030 & 803.4590 & 803.4587 \\
\hline$\Delta m / z(\mathbf{p p m})$ & 0.9 & 2.8 & 0.9 & -0.9 & 0.4 & 4.0 \\
\hline Retention time $(\mathrm{min})$ & 3.58 & 3.95 & $4.1-4.65$ & $4.2-4.4$ & 4.77 \\
\hline Percentage & 0.83 & 0.06 & 2.33 & 0.33 & 2.38 & 94.08 \\
\hline & & $* m / z$ for $[\mathrm{M}-\mathrm{H}]^{-}$.
\end{tabular}

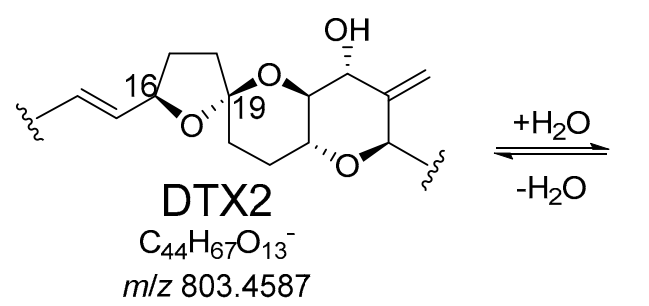

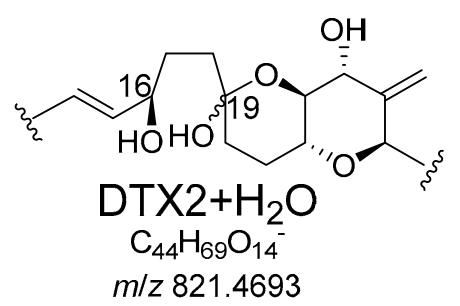

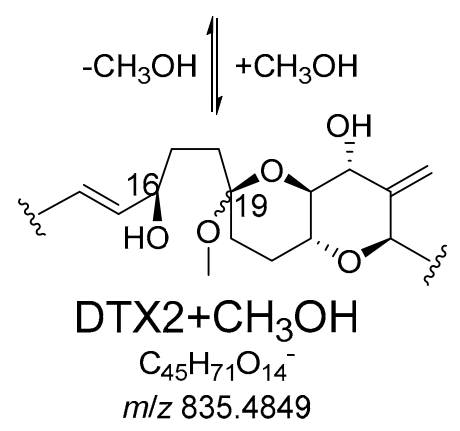

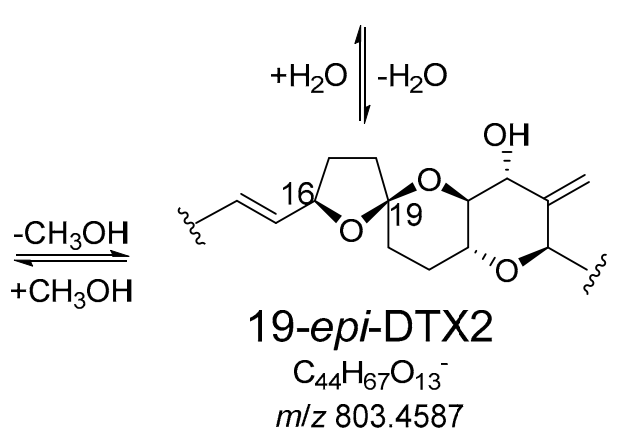

Figure 3. Scheme showing a possible route for interconversion of DTX2 and 19-epi-DTX2 via ring-opening of the ketal at C-19 (a standard ketal-hemiketal equilibration reaction), mediated by water and $\mathrm{MeOH}$. The $m / z$ values and elemental compositions are for the corresponding $[\mathrm{M}-\mathrm{H}]^{-}$ions.

A contaminant was visible in the LC-UV $(210 \mathrm{~nm})$ trace (Figure S4) that eluted just after DTX2, but this was not detected by LC-HRMS and was not identified. ${ }^{1} \mathrm{H}$ NMR spectroscopy did not reveal the presence of any major impurities, although minor olefinic resonances were detectable with a total relative intensity of $\sim 5 \%$ for DTX2 (Figures S6-S10), closely paralleling purity estimates based on LC-HRMS. Unfortunately, 1D ${ }^{1} \mathrm{H}$ NMR spectroscopy is not ideal for detecting small amounts of contaminants that are closely related structurally to the main component, as the majority of the resonances of the contaminants are very similar to those of the major component. Overall, the method was reduced from an eight- to a five-step procedure, with recoveries increased from $\sim 40$ to $\sim 68 \%$, relative to the method of Beach et al. [26], and with a purity of $>95 \%$ (Figure 2, Table 1). 


\subsection{Isolation of $O A$ and DTX1 from Prorocentrum lima}

\subsubsection{P. lima Culturing}

A study was performed on the growth and toxin accumulation of P. lima strain CCMI-1036 over $\sim 1.5$ years, and the results show maximum cell densities $\left(\sim 70,000\right.$ cells $\left.\mathrm{mL}^{-1}\right)$ were achieved after $\sim 5$ months of growth (Figure 4), after which cell counts plateaued for $\sim 7$ months, and then started to decline. Over the study period, toxin concentrations continued to increase steadily up until 11 months (381 d) of growth. After $381 \mathrm{~d}$ and up until $576 \mathrm{~d}$ (the final 6.5 months of the study) the increase in toxin levels was less significant.

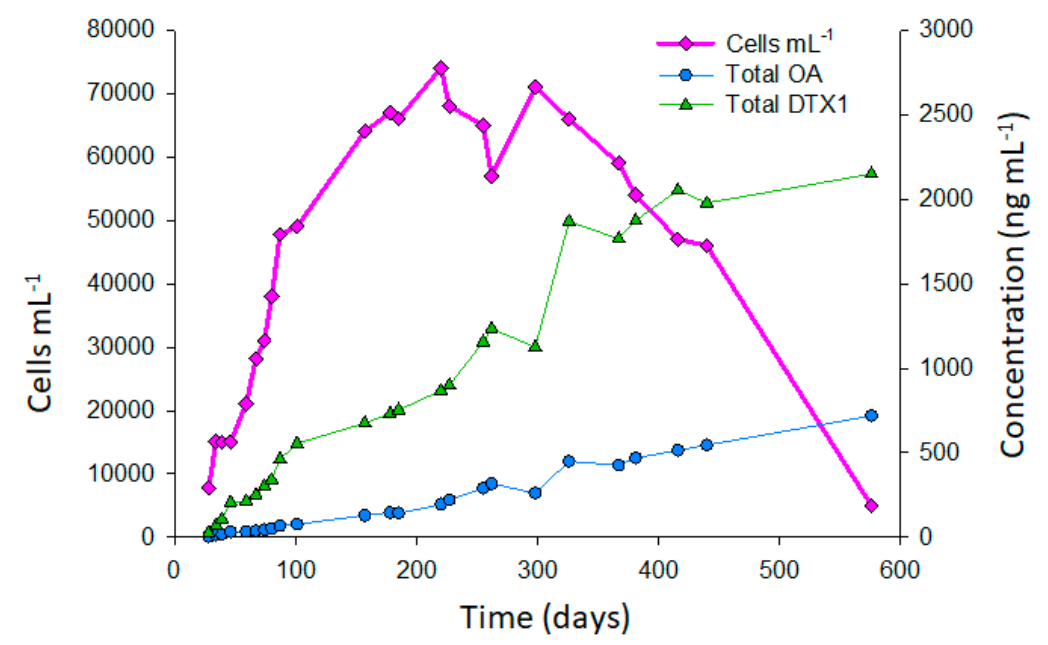

Figure 4. P. lima cell counts and toxin accumulation over $\sim 1.5$ years.

The culture produced OA, DTX1, and their esters, with the esters of both OA and DTX1 comprising $\sim 40-50 \%$ of the total toxin content. P. lima strains typically produce OA as the predominant toxin [15], but for this strain, DTX1 was dominant, being 3-fold higher than OA (Figure 4). Although the growth was slow $\left(0.028 \mathrm{~d}^{-1}\right)$, toxin accumulation was relatively high, with $\sim 0.7$ and $2.1 \mathrm{mg} \mathrm{L}^{-1} \mathrm{OA}$ and DTX1 (including their esters), respectively, detected after $\sim 1.5$ years.

A previous study of the growth and toxin accumulation in A. spinosum showed that AZAs were adsorbed onto the culture flask surface, once the cells lysed and the toxin was released into the medium, leading to a decline in toxin concentrations over the sampling period [35]. The same culture flasks were used in this study, and no decline in toxin concentrations was observed, indicating that adsorption was not an issue for the OA group toxins. In a previous study, however, it was noted that OA derivatives (especially 7-deoxyOA) are very liable to be adsorbed to the walls of plastic containers when performing protein phosphatase inhibition studies [36].

\subsubsection{Purification}

A previously published method [26] described a six-step procedure for purification of OA from Prorocentrum concavum (which mainly produces OA) biomass. Although no semi-preparative HPLC was required in this procedure, notable losses of toxin occurred after the initial large-scale vacuum-assisted silica LC step. In the same study, DTX1 was purified from P. lima biomass, also in a six-step procedure, using semi-preparative HPLC as the final clean-up step [26].

In the new method, the culture was treated with base to hydrolyse ester derivatives to the parent compounds, eliminating the need to perform a separate cell lysis step. Following neutralization, HP-20 resin was added to adsorb the toxins, and the recovered resin was eluted. Initial trials to assess the use of a SAX stationary phase, as in the method employed for the isolation of DTX2 from shellfish, resulted in significant losses of toxin $(\sim 40 \%)$ (data not shown). As an alternative, an alumina stationary 
phase was assessed and found to produce superior recoveries $(\sim 90 \%)$, and acted as an efficient clean-up ( $\sim 85 \%)$ step (Table 3$)$. This stationary phase was found to be effective previously in the purification of OA and DTX2 from HP-20 resin extracts [28]. The sample was then chromatographed on LH-20, resulting in a clean-up of $\sim 60 \%$, and recoveries of $\sim 95 \%$. As in the purification of DTX2, the final semi-preparative HPLC step employed an acidic ( $\mathrm{pH} 3.3)$ mobile phase that resulted in good peak shape and sufficient separation of OA and DTX1 from other sample impurities. Recoveries were good $(\sim 90 \%)$, indicating that there were no major acid instability issues (Table 3 ).

Table 3. Batch summary for isolation of OA and DTX1 from P. lima, as assessed by LC-HRMS (Section 3.5.1).

\begin{tabular}{|c|c|c|c|c|c|c|c|c|}
\hline & $\begin{array}{l}\text { Weight } \\
\text { (mg) }\end{array}$ & $\begin{array}{c}\text { Clean-up } \\
\left(100 \times\left(W_{i}-\right.\right. \\
\left.\left.W_{f}\right) / W_{i}\right)(\%)\end{array}$ & $\begin{array}{c}\text { OA } \\
(\mathrm{mg})\end{array}$ & $\begin{array}{c}\text { Step } \\
\text { Recovery } \\
(\%) \\
\end{array}$ & $\begin{array}{c}\text { Purity } \\
(\%)\end{array}$ & $\begin{array}{c}\text { DTX1 } \\
\text { (mg) }\end{array}$ & $\begin{array}{c}\text { Step } \\
\text { Recovery } \\
(\%)\end{array}$ & $\begin{array}{c}\text { Purity } \\
\text { (\%) }\end{array}$ \\
\hline Culture (4.5 L) & & & 3.3 & & & 10.5 & & \\
\hline Step 1 (HP-20 resin extract) & 322 & & 3.2 & & 1.0 & 10.2 & & 3.2 \\
\hline Step 2 (alumina/SPE) & 47.2 & 85.3 & 2.9 & 90.6 & 6.1 & 8.9 & 87.3 & 18.9 \\
\hline Step 3 (LH-20) & 19.5 & 58.7 & 2.8 & 96.6 & 14.4 & 8.5 & 95.5 & 43.6 \\
\hline Step 4 (semi-prep HPLC) & & & 2.5 & 89.3 & * 98.5 & 8.0 & 94.1 & ^ 97.3 \\
\hline$\%$ Recovery & & & 75.8 & & & 76.2 & & \\
\hline
\end{tabular}

Purity analysis of the OA by LC-HRMS and LC-UV indicated that purities were $>95 \%$ (Table 4 ; Figures S11-S13). The 19-epimer of OA $(\sim 1.4 \%)$ was present, as was another isomer $(<1 \%)$ that eluted prior to the 19-epimer (Table 4; Figures S11 and S12). DTX1 isomers eluted just after the OA peak in the semi-preparative HPLC, that likely contaminated the OA fractions, and this explains the presence $(<1 \%)$ of DTX1 (due to subsequent equilibration of the DTX1 isomers back to DTX1) in the final purified sample of OA (Table 4; Figures S11 and S12). In light of the subsequent stability study on DTX2 (Section 2.1), it is possible that these DTX1 isomers arose through acid-catalysed isomerisation of DTX1 during purification. In addition, two isomeric peaks of $\mathrm{OA}+\mathrm{MeOH}$ were also detected in the sample (Table 4; Figures S11 and S12). ${ }^{1} \mathrm{H}$ NMR analysis of the OA was consistent with the high purity of this material. Minor olefinic signals were present in the same region as for the DTX2 (Figures S6-S10), but these amounted to only $\sim 1 \%$ of the intensity of the main olefinic signals, consistent with the results of the LC-HRMS analyses.

Table 4. LC-HRMS (Section 3.5.2) analysis of purified OA (after NMR analysis, Figure S12).

\begin{tabular}{|c|c|c|c|c|c|c|c|}
\hline Toxin & \multicolumn{2}{|c|}{$\mathrm{OA}+\mathrm{MeOH}$} & DTX1 Isomer & DTX1 & OA Isomer & 19-epi-OA & OA \\
\hline Accurate mass $(m / z) *$ & \multicolumn{2}{|c|}{835.4822} & 817.4744 & 817.4744 & 803.4577 & 803.4587 & 803.4588 \\
\hline$\Delta m / z(\mathrm{ppm})$ & \multicolumn{2}{|c|}{-3.3} & 0.0 & 0.0 & -1.3 & 0.0 & 0.1 \\
\hline Retention time (min) & 3.95 & 4.36 & 4.65 & 5.32 & 4.34 & 4.43 & 4.54 \\
\hline Percentage & 0.08 & 0.04 & 0.07 & 0.18 & 0.33 & 1.38 & 97.91 \\
\hline
\end{tabular}

Purity analysis of the DTX1 by LC-HRMS and LC-UV indicated that purities were $>95 \%$ (Table 5; Figures S14-S16). The 19-epimer of DTX1 ( 2\%) was present, as was another isomer $(\sim 0.6 \%)$ that eluted prior to the 19-epimer (Table 5; Figures S14 and S15). An additional peak was present $(0.09 \%)$ in the LC-HRMS in the purified DTX1 sample that corresponded to 7-deoxyOA (Table 5 and Figures S14 and S15), a compound that has previously been reported in P. lima [36,37]. LC-HRMS analysis also showed the presence of trace levels of DTX1 + MeOH $(0.08 \%)$. As with OA, ${ }^{1} \mathrm{H}$ NMR analysis was consistent with DTX1 at high purity (Figures S6-S10), and indicated only low levels of related contaminants. 
Table 5. LC-HRMS (Section 3.5.2) analysis of purified DTX1 (after NMR analysis, Figure S15).

\begin{tabular}{|c|c|c|c|c|c|}
\hline Toxin & DTX1 + MeOH & 7-deoxyOA & DTX1 Isomer & 19-epi-DTX1 & DTX1 \\
\hline Accurate mass $(m / z) *$ & 849.5032 & 787.4612 & 817.4731 & 817.4757 & 817.4746 \\
\hline$\Delta m / z(\mathrm{ppm})$ & 3.0 & -3.3 & -1.5 & 1.6 & 0.3 \\
\hline Retention time (min) & 4.46 & 5.39 & 4.60 & 5.07 & 5.31 \\
\hline Percentage & 0.08 & 0.09 & 0.60 & 2.04 & 97.19 \\
\hline
\end{tabular}

Overall, a method was developed that employed a four-step procedure (Figure 5), with recoveries of $\sim 76 \%$ and purities of 98.2 and $97.2 \%$ (assuming 1:1 relative molar responses for the detected impurities) for OA and DTX1, respectively (Tables 4 and 5).

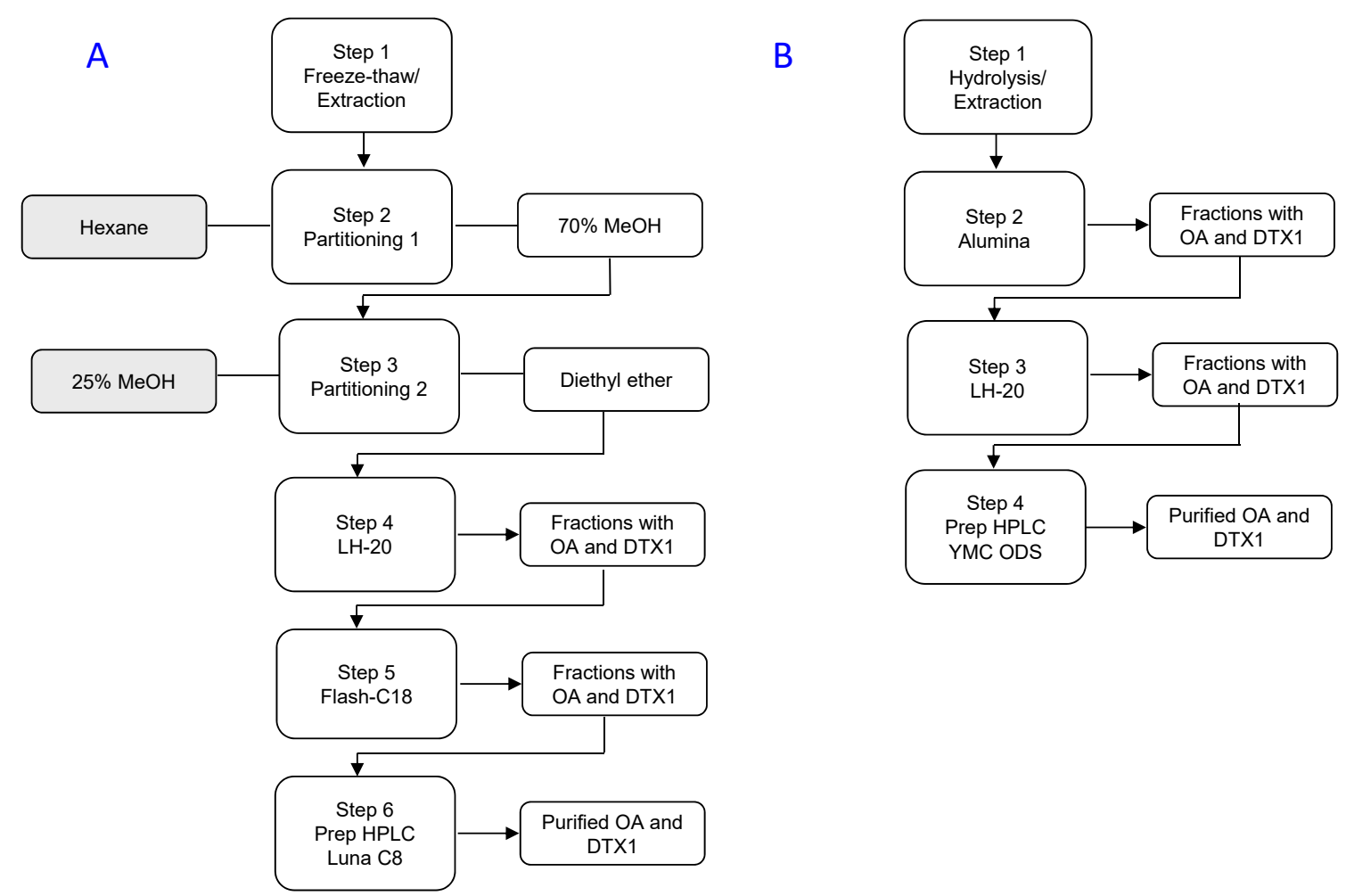

Figure 5. Isolation of OA and dinophysistoxin 1 (DTX1) from P. lima showing: (A) the procedure published by Beach et al. [26], and; (B) the improved method.

Given the susceptibility to acid-catalysed isomerisation of these toxins, it would be advisable to avoid exposure to acids in the late stages of purification of OA/DTXs. The formation of isomers would be reduced under neutral conditions in the final semi-preparative HPLC step; however, a neutral mobile phase results in broader peaks and poorer resolution from impurity peaks, thereby leading to reduced efficiencies and yields.

\section{Materials and Methods}

\subsection{Reagents}

Solvents (LC-MS grade) were from Labscan (Dublin, Ireland) and Fisher Scientific (Whitby, ON, Canada). Distilled water was further purified using the Barnstead nanopure diamond UV (Thermo Scientific, Des Moines, IA, USA) and Milli-Q (Millipore Corp., Billerica, MA, USA) purification systems. Formic acid $(\geq 98 \%)$, ammonium formate $(>98 \%)$, sodium hydroxide, Diaion HP-20 polymeric resin $(\geq 0.25 \mathrm{~mm})$, ammonium acetate $(97 \%)$, and SAX were from Sigma-Aldrich (Steinheim, 
Germany and Oakville, ON, Canada). Formic acid (98\%) was from Honeywell (Oakville, ON, Canada). Hydrochloric acid was from VWR (Fontenay-sous-bois, France), while ammonium bicarbonate (99\%) and ammonium hydroxide were from Acros (Trenton, NJ, USA). Aluminium oxide 90 active basic and acetic acid were from Merck (Darmstadt, Germany). Sephadex LH-20 was from GE Healthcare (Uppsala, Sweden). CRMs OA-d, DTX1-b, and DTX2-b were from the National Research Council (Halifax, NS, Canada) [26].

\subsection{Isolation of DTX2 from Shellfish}

Cooked whole-mussel tissue from M. edulis collected in 2010, from the southwest of Ireland, was dissected to yield $\sim 400 \mathrm{~g}$ of hepatopancreas, which was homogenised and freeze-dried (117 g). $\mathrm{MeOH}(500 \mathrm{~mL})$ and $2.5 \mathrm{M} \mathrm{NaOH}(62.5 \mathrm{~mL})$ in $90 \% \mathrm{MeOH}$ was added to the sample, and sonicated for $5 \mathrm{~min}$. The sample was then placed in a water bath set at $76^{\circ} \mathrm{C}$ for $30 \mathrm{~min}$. Once the sample cooled, $2.5 \mathrm{M} \mathrm{HCl}(62.5 \mathrm{~mL})$ in $\mathrm{MeOH}$ was added. The suspension was filtered, and the retentate further extracted with $\mathrm{MeOH}(3 \times 500 \mathrm{~mL})$ using a Waring blender. The four methanolic extracts were combined and evaporated in vacuo. The residue was partitioned between hexane $(200 \mathrm{~mL})$ and $\mathrm{MeOH}-\mathrm{H}_{2} \mathrm{O}(9: 1,200 \mathrm{~mL})$. The $\mathrm{MeOH}-\mathrm{H}_{2} \mathrm{O}$ layer was evaporated in vacuo and the residue dissolved in EtOAc $(200 \mathrm{~mL})$ and partitioned with $\mathrm{H}_{2} \mathrm{O}(200 \mathrm{~mL})$. The EtOAc layer was evaporated in vacuo and the residue dissolved in 10:3 $\mathrm{H}_{2} \mathrm{O}-\mathrm{MeOH}(28.5 \mathrm{~mL})$, containing $0.7 \mathrm{~g}$ ammonium bicarbonate, and loaded onto a strong anion exchange (SAX) column $(20 \mathrm{~g})$. The column was washed with $\mathrm{H}_{2} \mathrm{O}$ $(\sim 50 \mathrm{~mL})$ until the eluate was colourless. The DTX2 was then eluted using a stepped gradient of acidic (formic acid) $\mathrm{H}_{2} \mathrm{O}$ at pH $3(1 \times 50 \mathrm{~mL}), \mathrm{pH} 2.8(1 \times 50 \mathrm{~mL})$ and $\mathrm{pH} 2.6(8 \times 50 \mathrm{~mL})$, analysing each fraction by LC-HRMS (Section 3.5.1). The fractions (4-10, $\mathrm{pH} 2.6)$ containing the toxin were combined $(\sim 350 \mathrm{~mL})$, and the $\mathrm{pH}$ adjusted to 7 using $\mathrm{NaOH}$. The DTX2 was recovered by partitioning with $\mathrm{CH}_{2} \mathrm{Cl}_{2}$. Final purification of DTX2 was achieved by semi-preparative HPLC (Shimadzu 10AVp; Kyoto, Japan), with photodiode array (PDA) detection $(210 \mathrm{~nm})$, using a YMC-Pack ODS-AQ $(250 \times 10 \mathrm{~mm}$, $5 \mu \mathrm{m}$; YMC, Kyoto, Japan) column eluted with 0.9:1 $\mathrm{CH}_{3} \mathrm{CN}-\mathrm{H}_{2} \mathrm{O}$ (pH adjusted to 3.3 using formic acid) at $4 \mathrm{~mL} \mathrm{~min}^{-1}$ for $65 \mathrm{~min}$. The column was flushed with $\mathrm{MeOH}$ for $5 \mathrm{~min}$, returned to the initial conditions and held for $5 \mathrm{~min}$ to equilibrate the system. The column temperature was $30^{\circ} \mathrm{C}$. The organic solvent was evaporated in vacuo from the combined DTX2 fractions, and the pH of the aqueous sample was adjusted to 7 using $\mathrm{NaOH}$, to limit acid instability.

Purified DTX2 was recovered by loading the aqueous sample dropwise onto a solid-phase extraction cartridge (Oasis $\mathrm{HLB}, 200 \mathrm{mg})$, washing with $\mathrm{H}_{2} \mathrm{O}(20 \mathrm{~mL})$ to remove the buffer, and eluting with $\mathrm{MeOH}(25 \mathrm{~mL})$. Removal of solvent by evaporation in vacuo afforded purified DTX2 (7.3 mg) as a white solid.

\section{9-epi-DTX2 Kinetics}

An aliquot of 19-epi-DTX2 available from previous work [26] was dissolved in $\mathrm{MeOH}(50 \mu \mathrm{L})$ in an LC vial insert, formic acid $(0.5 \mu \mathrm{L})$ was added, and the vial was placed in the sample tray and analysed periodically by LC-MS/MS. A sample of 19-epi-DTX2 in MeOH without acidification was used as a reference standard. Kinetic data were analysed with SigmaPlot 12.5 (Systat, San Jose, CA, USA) by fitting to a 3-parameter exponential decay curve (Figure S5).

LC-MS/MS analysis was performed on an Agilent 1260 LC (Palo Alta, CA, USA) coupled to an AB-Sciex (Concord, ON, Canada) 4000 QTRAP MS equipped with a turbospray ionization source. The autosampler temperature was maintained at $10^{\circ} \mathrm{C}$ and $2 \mu \mathrm{L}$ injection volumes were used. A Luna C18(2)HST column $\left(50 \times 2 \mathrm{~mm}\right.$, i.d., $2.5 \mu \mathrm{m}$; Phenomenex, Torrance, CA, USA) maintained at $20^{\circ} \mathrm{C}$ was eluted at $300 \mu \mathrm{L} \mathrm{m^{-1 }}$ with a 7 min linear gradient of $15-100 \% \mathrm{~B}$, using $5 \mathrm{mM}$ ammonium acetate in $\mathrm{H}_{2} \mathrm{O}(\mathrm{A})$ and $95 \% \mathrm{CH}_{3} \mathrm{CN}(\mathrm{B})$ at $\mathrm{pH} 6.8$ as the mobile phase. MS detection used selected reaction monitoring with negative polarity electrospray ionization as follows; temperature $500{ }^{\circ} \mathrm{C}$; curtain gas 30 psi; -4.5 kV spray voltage; GS1 40 psi; GS2 60 psi; DP -50 V; and CE values of -65 and -95 eV for the $803.5 \rightarrow 255.1$ and $803.5 \rightarrow 113.1$ transitions, respectively, each analysed with a 65 ms dwell time. 


\subsection{P. lima Culturing}

Cultures of a P. lima strain (CCMI-1036), isolated from the southwest coast of Ireland, were grown in $5 \mathrm{~L}$ (Corning cellSTACKs, Lowel, MA, USA) culture flasks, each containing 2.2 L of L1 culture medium [38] (at $18{ }^{\circ} \mathrm{C}$, photoperiod 12:12 light:dark), for $\sim 1.5$ years (with no addition of nutrients over the study period).

\section{Culture Sampling}

For cell densities, the cultures were sampled by transferring $500 \mu \mathrm{L}$ of well-mixed culture into a $1.5 \mathrm{~mL}$ centrifuge tube containing $400 \mu \mathrm{L}$ seawater and $100 \mu \mathrm{L}$ Lugol's iodine. As cultures became denser, the ratio of seawater to culture was increased. Cells were counted on a Sedgwick rafter by visual microscopy (Olympus model BX53, Madison, WI, USA). Growth rate, as the exponent of the exponential equation, was calculated from cell density time series data by exponential regression of cell counts versus time for a defined period of exponential growth (day 46-87) using Microsoft Excel (2016).

For LC-HRMS analysis of OA and DTX1, the cultures were sampled in duplicate, one for analysis of the free toxins and the other for total toxins, i.e., including esters. Into two HPLC vials, containing $900 \mu \mathrm{L}$ $\mathrm{MeOH}, 100 \mu \mathrm{L}$ of well-mixed culture was added, vortex-mixed for $0.5 \mathrm{~min}$, and stored at $-18{ }^{\circ} \mathrm{C}$ until analysis. Prior to analysis, the samples taken for total toxin were hydrolysed to convert the esters to the parent compounds by addition of $\mathrm{NaOH}(2.5 \mathrm{M} ; 125 \mu \mathrm{L})$, then heated in a water bath $\left(76^{\circ} \mathrm{C}\right.$; $20 \mathrm{~min})$, cooled, and neutralised with $\mathrm{HCl}(2.5 \mathrm{M} ; 125 \mu \mathrm{L})$.

\subsection{Isolation $O A$ and DTX1 from P. lima}

The contents of two cell stacks ( $\sim 4.5 \mathrm{~L})$ were transferred to a glass Erlenmeyer flask. To convert OA and DTX1 esters, $500 \mathrm{~mL}$ of $2.5 \mathrm{M} \mathrm{NaOH}$ was added. After $24 \mathrm{~h}$, once full conversion of the esters had occurred, as indicated by LC-HRMS analysis, the sample was neutralised using $2.5 \mathrm{M} \mathrm{HCl}$. The sample was filtered through a $20 \mu \mathrm{m}$ mesh. LC-HRMS analysis of both the filtrate and biomass showed that $>95 \%$ of the toxins were present in the filtrate. Activated HP-20 resin (50 g loosely packed into a $20 \mu \mathrm{m}$ mesh bag) was placed in the filtrate and left to stir for $2 \mathrm{~d}$, after which time $>95 \%$ of toxin had adsorbed onto the resin. The resin was rinsed with water and dried. Toxins were eluted by sonicating for $0.5 \mathrm{~h}$ in $50 \mathrm{~mL} \mathrm{MeOH}(\times 5)$, filtering through Whatman filter paper, and the solvent evaporated in vacuo to give an oily residue $(0.32 \mathrm{~g})$.

The residue was dissolved in a minimum amount of $\mathrm{MeOH}$ and loaded onto $15 \mathrm{~g}$ of alumina slurried in $\mathrm{CH}_{2} \mathrm{Cl}_{2}$. The column was eluted with 1:1 $\mathrm{MeOH}-\mathrm{CH}_{2} \mathrm{Cl}_{2}, \mathrm{MeOH}, 4: 1 \mathrm{MeOH}-\mathrm{H}_{2} \mathrm{O}$, 1:1 $\mathrm{MeOH}-\mathrm{H}_{2} \mathrm{O}$, and 1:1 MeOH-H ${ }_{2} \mathrm{O}$ (pH 11 ammonium hydroxide) (50 mL of each). The aqueous fractions (4:1 $\mathrm{MeOH}-\mathrm{H}_{2} \mathrm{O}$ and 1:1 $\mathrm{MeOH}-\mathrm{H}_{2} \mathrm{O}$, eluates 3-9) containing the toxins were combined $(350 \mathrm{~mL})$, and the $\mathrm{MeOH}$ removed by evaporation in vacuo. The $\mathrm{pH}$ of the remaining aqueous layer was adjusted from 10.2 to 7 with $0.1 \mathrm{M}$ acetic acid. The OA and DTX1 were recovered by loading onto a solid-phase extraction cartridge (Oasis HLB, $200 \mathrm{mg}$ ), washing with $\mathrm{H}_{2} \mathrm{O}(20 \mathrm{~mL})$ to remove the buffer, and eluting with $\mathrm{MeOH}(25 \mathrm{~mL})$. The dry residue $(\sim 0.02 \mathrm{~g})$ was loaded onto an LH-20 column $(22 \times 2.7 \mathrm{~cm})$, and eluted with $\mathrm{MeOH}$, with the first 15 min discarded as waste, and 3-min fractions collected thereafter. Toxins eluted in fractions 4-6. These fractions were combined $(\sim 9 \mathrm{~mL})$, and the $\mathrm{MeOH}$ removed by evaporation in vacuo. Final purification of OA and DTX1 was achieved by semi-preparative HPLC (Shimadzu 10AVp), with UV detection $(210 \mathrm{~nm})$, using a YMC-Pack ODS-AQ $(250 \times 10 \mathrm{~mm}, 5 \mu \mathrm{m})$ column, eluted with 1:1 $\mathrm{CH}_{3} \mathrm{CN}-\mathrm{H}_{2} \mathrm{O}\left(\mathrm{pH} 3.3\right.$, formic acid) at $4 \mathrm{~mL} \mathrm{~min}{ }^{-1}$. The column temperature was $30^{\circ} \mathrm{C}$. The organic solvent was evaporated from the combined fractions, and the $\mathrm{pH}$ of the remaining aqueous residue was adjusted to 7 using $\mathrm{NaOH}$ to limit acid instability. The toxins were recovered by loading the aqueous samples dropwise onto SPE cartridges (Oasis HLB, $200 \mathrm{mg}$ ), washing with $\mathrm{H}_{2} \mathrm{O}(20 \mathrm{~mL})$ to remove the buffer, and eluting with $\mathrm{MeOH}(25 \mathrm{~mL})$. Removal of solvent by evaporation in vacuo afforded purified OA $(2.5 \mathrm{mg})$ and DTX1 $(8 \mathrm{mg})$ as white solids. 


\subsection{LC-HRMS}

\subsubsection{Acidic Method}

Analysis was performed using a Waters Acquity UPLC coupled to a Xevo G2-S QToF monitoring in MSe mode (negative ionization, 100-1200 m/z), using leucine enkephalin as the reference compound. The cone voltage was $40 \mathrm{~V}$, collision energy was $50 \mathrm{eV}$, the cone and desolvation gas flows were set at 0 and $600 \mathrm{~L} \mathrm{~h}^{-1}$, respectively, and the source temperature was $120^{\circ} \mathrm{C}$.

Chromatography was performed with an Acquity UPLC BEH C18 $(50 \times 2.1 \mathrm{~mm}, 1.7 \mu \mathrm{m})$ column (Waters, Wexford, Ireland). Binary gradient elution was used, with mobile phase A consisting of $\mathrm{H}_{2} \mathrm{O}$ and mobile phase $\mathrm{B}$ of $\mathrm{CH}_{3} \mathrm{CN}(95 \%)$ in $\mathrm{H}_{2} \mathrm{O}$ (both containing $2 \mathrm{mM}$ ammonium formate and $50 \mathrm{mM}$ formic acid). The gradient was from 5 to $90 \%$ B over $2 \mathrm{~min}$ at $0.3 \mathrm{~mL} \mathrm{~min}^{-1}$, held for $1 \mathrm{~min}$, and returned to the initial conditions and held for $1 \mathrm{~min}$ to equilibrate the system (total run time $4 \mathrm{~min}$ ). The injection volume was $2 \mu \mathrm{L}$ and the column and sample temperatures were 25 and $6{ }^{\circ} \mathrm{C}$, respectively. Quantitation using CRMs was performed using Targetlynx software. Purities were calculated based on the assumption of 1:1 relative molar responses for the detected impurities.

\subsubsection{Neutral Method}

Analysis was performed with a Q Exactive-HF Orbitrap mass spectrometer equipped with a HESI-II heated electrospray ionization interface (ThermoFisher Scientific, Waltham, MA, USA) using an Agilent $1200 \mathrm{LC}$ system including a binary pump, autosampler (sample tray $10^{\circ} \mathrm{C}$ ) and column oven (Agilent, Palo Alto, CA, USA). Analyses were performed with a Synergi Max-RP C12 column $\left(50 \times 2 \mathrm{~mm}, 2.5 \mu \mathrm{m}\right.$; Phenomenex, Torrance, $\mathrm{CA}$, USA) held at $25^{\circ} \mathrm{C}$ with mobile phases A and $\mathrm{B}$ of $\mathrm{H}_{2} \mathrm{O}$ and 95:5 $\mathrm{CH}_{3} \mathrm{CN}-\mathrm{H}_{2} \mathrm{O}$, respectively, each of which contained $\mathrm{NH}_{4} \mathrm{OAc}(5 \mathrm{mM})$. Linear gradient elution

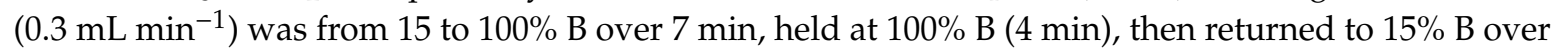
$0.1 \mathrm{~min}$, with a hold at $15 \% \mathrm{~B}(3.9 \mathrm{~min}$ ) to equilibrate the column (total run time $15 \mathrm{~min}$ ). The injection volume was $5 \mu \mathrm{L}$. The mass spectrometer was operated in negative mode and calibrated from $\mathrm{m} / \mathrm{z} 69$ to 1780 with the spray voltage $-2.7 \mathrm{kV}$, probe heater temperature $300^{\circ} \mathrm{C}$, capillary temperature $350^{\circ} \mathrm{C}$, and with sheath and auxiliary gas flow rates of 40 and 15 units, respectively, and MS data acquired from 2 to $11 \mathrm{~min}$. Mass spectral data were collected in alternating full-scan/data-independent acquisition (FS/DIA) scan mode using an FS scan range of $m / z$ 200-1200, a resolution setting of 60,000, AGC target of $1 \times 10^{6}$ and max IT of $200 \mathrm{~ms}$. The DIA data were collected using a resolution setting of 15,000, AGC target of $1 \times 10^{5}$, max IT set to $100 \mathrm{~ms}$ and normalised collision energy $35 \mathrm{eV}$. Isolation windows were $25 \mathrm{~m} / \mathrm{z}$ wide and centred at $\mathrm{m} / \mathrm{z} 612,635,658,682,705,728,752,775,798,822,845,868,892,892$, and 938. DIA chromatograms were extracted ( $\pm 5 \mathrm{ppm})$ for product ions at $m / z 255.1238$ and 239.1289.

\section{6. $L C-U V$}

Purified samples $\left(\sim 0.5 \mathrm{mg} \mathrm{mL}^{-1}, 10 \mu \mathrm{L}\right)$ were injected onto a LC (Shimadzu 10AVp), with UV detection $(210 \mathrm{~nm})$, using a Luna phenyl-hexyl $(250 \times 4.6 \mathrm{~mm}, 5 \mu \mathrm{m}$; Phenomenex, Torrance, CA, USA) column eluted with 0.9:1 $\mathrm{CH}_{3} \mathrm{CN}-\mathrm{H}_{2} \mathrm{O}\left(\mathrm{pH} 3.3\right.$, formic acid) at $1 \mathrm{~mL} \mathrm{~min}^{-1}$. The column temperature was $30^{\circ} \mathrm{C}$.

\subsection{NMR Spectroscopy}

Samples were received in $\mathrm{MeOH}$ and transferred to pre-weighed scintillation vials, rinsing the ampoules with $\mathrm{MeOH}(3 \times 0.5 \mathrm{~mL})$. The solvent was evaporated under a stream of dry $\mathrm{N}_{2}$, weighed, dissolved in $\mathrm{CD}_{3} \mathrm{OD}(750 \mu \mathrm{L}, 99.5$ atom \% D; Cambridge Isotope Laboratories, Andover, MA, USA), and transferred to NMR tubes (5 mm i.d.). ${ }^{1} \mathrm{H}$ NMR spectra were acquired on a Bruker DRX-500 NMR spectrometer at $500.13 \mathrm{MHz}$ (64 scans, $20^{\circ} \mathrm{C}$ ) using Icon NMR in Bruker TopSpin 3.2, and data were processed with TopSpin 3.6.2. 


\section{Conclusions}

Methods for the purification of OA group toxins from shellfish (M. edulis) and microalgae (P. lima) were enhanced, leading to a reduction in the number of purification steps and an increase in yields. From $400 \mathrm{~g}$ of contaminated M. edulis hepatopancreas, $7.3 \mathrm{mg}$ of DTX2 was purified using a five-step procedure, involving partitioning and column chromatography, with yields of $\sim 68 \%$. A comparison of alumina and SAX stationary phases showed that improved purification was achieved using a SAX stationary phase, allowing progression to the final semi-preparative HPLC clean-up.

The growth and toxin production of an Irish strain of P. lima was monitored over 1.5 years, showing an increase in OA, DTX1, and their esters (that comprised $\sim 50 \%$ of the total toxin content) over the testing period. The results indicate that optimum harvesting time occurs after $\sim 1$ year of growth. From $4.5 \mathrm{~L}$ of culture (harvested after 1.5 years), $2.5 \mathrm{mg}$ of OA and $8 \mathrm{mg}$ of DTX1 were purified, using a four-step purification procedure, with yields of $\sim 76 \%$. A comparison of alumina and SAX stationary phases showed higher yields were achieved using an alumina stationary phase, with sufficient purification to allow progression to semi-preparative HPLC clean-up.

An acidic method was used in the final semi-preparative HPLC step for all toxins, leading to greater efficiencies and higher yields. However, as these toxins are susceptible to acid-catalysed isomerization, impurities, in the form of isomers, were detected in the purified samples. Although replacing an acidic mobile phase with a neutral mobile phase at this stage may decrease the formation of such isomers, efficiencies and yields would be reduced.

The focus of this study was on the OA group toxins; however, future work could focus on describing the full metabolome and identification of other novel compounds produced by P. lima, that may have useful bioactive properties. The compounds purified in this study can be used to sustain supplies for the development of CRMs, and other areas of research such as toxicology and pharmacology.

Supplementary Materials: The following are available online at http:/www.mdpi.com/1660-3397/18/12/647/s1, Figure S1: LC-UV clean-up of DTX2 using alumina and sax chromatography, Figures S2 and S3: Purity analysis of DTX2 by LC-HRMS (acidic and neutral methods), Figure S4: Purity analysis of DTX2 by LC-UV, Figure S5: Kinetic analysis of 19-epi-DTX2 in acidic MeOH, Figures S6-S10: 1H NMR spectra of OA, DTX1, and DTX2 in $\mathrm{CD}_{3} \mathrm{OD}$, Figures S11 and S12: Purity analysis of OA by LC-HRMS (acidic and neutral methods), Figure S13: Purity analysis of OA by LC-UV, Figures S14 and S15: Purity analysis of DTX1 by LC-HRMS (acidic and neutral methods), Figure S16: Purity analysis of DTX1 by LC-UV.

Author Contributions: Conceptualization, J.K. and C.O.M.; methodology, J.K. and C.O.M.; provision of P. lima culture and advice on culturing, R.S.; experimental work, J.K., S.B., C.N., I.R., and E.J.W.; writing of manuscript, J.K., and C.O.M.; review and editing, J.K., E.J.W. and C.O.M. All authors have read and agreed to the published version of the manuscript.

Funding: This work was carried out as part of the MARBioFEED project, supported under the First Call for Transnational Research Projects within the Marine Biotechnology ERA-NET; project no. 604814. ("Enhanced Biorefining Methods for the Production of Marine Biotoxins and Microalgae Fish Feed").

Acknowledgments: The authors wish to thank Greta Gaiani and Amy McCoy for laboratory assistance, and Pearse McCarron for helpful discussions.

Conflicts of Interest: The authors declare no conflict of interest.

\section{References}

1. Fernandez, J.; Suarez-Gomez, B.; Souto, M.L.; Norte, M. Identification of new okadaic acid derivatives from laboratory cultures of Prorocentrum lima. J. Nat. Prod. 2003, 66, 1294-1296. [CrossRef] [PubMed]

2. López-Rosales, L.; Gallardo-Rodríguez, J.; Sánchez-Mirón, A.; Cerón-García, M.; Belarbi, E.; García-Camacho, F.; Molina-Grima, E. Simultaneous effect of temperature and irradiance on growth and okadaic acid production from the marine dinoflagellate Prorocentrum belizeanum. Toxins 2014, 6, 229-253. [CrossRef] [PubMed] 
3. Yasumoto, T.; Oshima, Y.; Sugawara, W.; Fukuyo, Y.; Oguri, H.; Igarashi, T.; Fujita, N. Identification of Dinophysis fortii as the causative organism of diarrhetic shellfish poisoning. Bull. Jpn. Soc. Sci. Fish. 1980, 46, 1405-1411. [CrossRef]

4. Reguera, B.; Riobó, P.; Rodríguez, F.; Díaz, P.A.; Pizarro, G.; Paz, B.; Franco, J.M.; Blanco, J. Dinophysis toxins: Causative organisms, distribution and fate in shellfish. Mar. Drugs 2014, 12, 394-461. [CrossRef]

5. Aune, T.; Yndestad, M. Diarrhetic shellfish poisoning. In Algal Toxins in Seafood and Drinking Water; Falconer, I.R., Ed.; Academic Press: London, UK, 1993; pp. 87-104.

6. Miles, C.O.; Wilkins, A.L.; Munday, R.; Dines, M.H.; Hawkes, A.D.; Briggs, L.R.; Sandvik, M.; Jensen, D.J.; Cooney, J.M.; Holland, P.T. Isolation of pectenotoxin-2 from Dinophysis acuta and its conversion to pectenotoxin-2 seco acid, and preliminary assessment of their acute toxicities. Toxicon 2004, 43, 1-9. [CrossRef]

7. Miles, C.O.; Wilkins, A.L.; Hawkes, A.D.; Jensen, D.J.; Cooney, J.M.; Larsen, K.; Petersen, D.; Rise, F.; Beuzenberg, V.; Lincoln MacKenzie, A. Isolation and identification of a cis-C8-diol-ester of okadaic acid from Dinophysis acuta in New Zealand. Toxicon 2006, 48, 195-203. [CrossRef]

8. Pizarro, G.; Paz, B.; Franco, J.M.; Suzuki, T.; Reguera, B. First detection of pectenotoxin-11 and confirmation of OA-D8 diol-ester in Dinophysis acuta from European waters by LC-MS/MS. Toxicon 2008, 52, 889-896. [CrossRef]

9. Hu, T.M.; Marr, J.; de Freitas, A.S.W.; Quilliam, M.A.; Walter, J.A.; Wright, J.L.C.; Pleasance, S. New diol esters isolated from cultures of the dinoflagellates Prorocentrum lima and Prorocentrum concavum. J. Nat. Prod. 1992, 55, 1631-1637. [CrossRef]

10. Reguera, B.; Velo-Suarez, L.; Raine, R.; Park, M.G. Harmful Dinophysis species: A review. Harmful Algae 2012, 14, 87-106. [CrossRef]

11. Regulation (EC) No 853/2004 of the European parliament and of the council of 29 April 2004 laying down specific hygiene rules for food of animal origin. Off. J. Eur. Union 2004, L139. Available online: https:/eur-lex.europa.eu/legal-content/EN/ALL/?uri=CELEX\%3A32004R0853 (accessed on 22 April 2020).

12. Commission Regulation (EU) No 15/2011 of 10th January 2011 amending Regulation (EC) No 2074/2005 as regards recognized testing methods for detecting marine biotoxins in live bivalve molluscs. Off. J. Eur. Union 2011, L6, 3-6. Available online: https://eur-lex.europa.eu/LexUriServ/LexUriServ.do?uri=OJ:L:2011:006:0003: 0006:EN:PDF (accessed on 22 April 2020).

13. Abal, P.; Louzao, C.M.; Suzuki, T.; Watanabe, R.; Vilariño, N.; Carrera, C.; Botana, A.M.; Vieytes, M.R.; Botana, L.M. Toxic action re-evaluation of okadaic acid, dinophysistoxin-1 and dinophysistoxin-2: Toxicity equivalency factors based on the oral toxicity study. Cell Physiol. Biochem. 2018, 49, 743-757. [CrossRef] [PubMed]

14. Bodero, M.; Bovee, T.F.H.; Wang, S.; Hoogenboom, R.L.A.P.; Klijnstra, M.D.; Portier, L.; Hendriksen, P.J.M.; Gerssen, A. Screening for the presence of lipophilic marine biotoxins in shellfish samples using the neuro-2a bioassay. Food Addit. Contam. Part A Chem. Anal. Control Expo. Risk Assess. 2018, 35, 351-365. [CrossRef] [PubMed]

15. Lee, T.C.H.; Fong, F.L.Y.; Ho, K.C.; Lee, F.W.F. The mechanism of diarrhetic shellfish poisoning toxin production in Prorocentrum spp.: Physiological and molecular perspectives. Toxins 2016, 8, 272. [CrossRef]

16. Salas, R.; Clarke, D. Review of DSP toxicity in Ireland: Long-term trend impacts, biodiversity and toxin profiles from a monitoring perspective. Toxins 2019, 11, 61. [CrossRef]

17. Cohen, P.; Holmes, C.F.B.; Tsukitani, Y. Okadaic acid: A new probe for the study of cellular regulation. TIBS 1990, 15, 98-102. [CrossRef]

18. Valdiglesias, V.; Prego-Faraldo, M.V.; Pásaro, E.; Méndez, J.; Laffon, B. Okadaic acid: More than a diarrheic toxin. Mar. Drugs 2013, 11, 4328-4349. [CrossRef]

19. Garcia, A.; Cayla, X.; Guergnon, J.; Dessauge, F.; Hospital, V.; Paz Rebollo, M.; Fleischer, A.; Rebollo, A. Serine/threonine protein phosphatases PP1 and PP2A are key players in apoptosis. Biochemie 2003, 85, 721-726. [CrossRef]

20. Kamat, P.K.; Rai, S.; Swarnkar, S.; Shukla, R.; Nath, C. Molecular and cellular mechanism of okadaic acid-induced neurotoxicity: A novel tool for Alzheimer's disease therapeutic application. Mol. Neurobiol. 2014, 50, 852-865. [CrossRef]

21. Quilliam, M.A.; Hardstaff, W.R.; Ishida, N.; McLachlan, J.L.; Reeves, A.R.; Ross, N.W.; Windust, A.J. Production of diarrhetic shellfish poisoning (DSP) toxins by Prorocentrum lima in culture and development of analytical methods. In Harmful and Toxic Algal Blooms; Yasumoto, T., Ed.; Intergovernmental Oceanograpohic Commission of UNESCO: Sendai, Japan, 1996; pp. 289-292. 
22. García-Portela, M.; Reguera, B.; Sibat, M.; Altenburger, A.; Rodríguez, F.; Hess, P. Metabolomic profiles of Dinophysis acuminata and Dinophysis acuta using non-targeted high-resolution mass spectrometry: Effect of nutritional status and prey. Mar. Drugs 2018, 16, 143. [CrossRef]

23. Park, M.G.; Kim, S.; Kim, H.S.; Myung, G.; Kang, Y.G.; Yih, W. First successful culture of the marine dinoflagellate Dinophysis acuminata. Aquat. Microb. Ecol. 2006, 45, 101-106. [CrossRef]

24. Hwang, B.S.; Kim, H.S.; Yih, W.; Jeong, E.J.; Rho, J.R. Acuminolide A: Structure and bioactivity of a new polyether macrolide from dinoflagellate Dinophysis acuminata. Org. Lett. 2014, 16, 5362-5365. [CrossRef] [PubMed]

25. Hu, T.; Doyle, J.; Jackson, D.; Marr, J.; Nixon, E.; Pleasance, S.; Quilliam, M.A.; Walter, J.A.; Wright, J.L.C. Isolation of a new diarrhetic shellfish poison from Irish mussels. J. Chem. Soc. Chem. Commun. 1992, 30, 39-41. [CrossRef]

26. Beach, D.G.; Crain, S.; Lewis, N.; LeBlanc, P.; Hardstaff, W.R.; Perez, R.; Giddings, S.D.; Martinez-Farina, C.F.; Stefanova, R.; Burton, I.W.; et al. Development of certified reference materials for diarrhetic shellfish poisoning toxins, part 1: Calibration solutions. J. AOAC Int. 2016, 99, 1-12. [CrossRef] [PubMed]

27. Larsen, K.; Petersen, D.; Wilkins, A.L.; Samdal, I.A.; Sandvik, M.; Rundberget, T.; Goldstone, D.; Arcus, V.; Hovgaard, P.; Rise, F.; et al. Clarification of the C-35 stereochemistries of dinophysistoxin-1 and dinophysistoxin-2, and its consequences for binding to protein phosphatase. Chem. Res. Toxicol. 2007, 20, 868-875. [CrossRef] [PubMed]

28. Rundberget, T.; Sandvik, M.; Larsen, K.; Pizzaro, G.; Reguera, B.; Castberg, T.; Gustad, E.; Loader, J.I.; Rise, F.; Wilkins, A.L.; et al. Extraction of microalgal toxins by large-scale pumping of seawater in Spain and Norway, and isolation of okadaic acid and dinophysistoxin-2. Toxicon 2007, 50, 960-970. [CrossRef]

29. Isobe, M.; Ichikawa, Y. Total synthesis of a marine toxic polyether okadaic acid. Yuki Gosei Kagaku Kyokaishi 1986, 44, 1155-1168. [CrossRef]

30. Pang, Y.; Fang, C.; Twiner, M.J.; Miles, C.O.; Forysth, C.J. Total synthesis of dinophysistoxin-2 and 2-epi-dinophysistoxin-2 and their PPase inhibition. Angew. Chem. Int. Ed. 2011, 50, 7631-7635. [CrossRef]

31. Wilkins, A.L.; Rehmann, N.; Torgersen, T.; Rundberget, T.; Keogh, M.; Petersen, D.; Hess, P.; Rise, F.; Miles, C.O. Identification of fatty acid esters of pectenotoxin-2 seco acid in blue mussels (Mytilus edulis) from Ireland. J. Agric. Food Chem. 2006, 54, 5672-5678. [CrossRef]

32. MARBioFEED. Available online: https://www.marine.ie/Home/site-area/research-funding/marinebiotechnology/marbiofeed-project (accessed on 22 April 2020).

33. Kilcoyne, J.; Keogh, A.; Clancy, G.; LeBlanc, P.; Burton, I.; Quilliam, M.A.; Hess, P.; Miles, C.O. Improved isolation procedure for azaspiracids from shellfish, structural elucidation of azaspiracid-6, and stability studies. J. Agric. Food Chem. 2012, 60, 2447-2455. [CrossRef]

34. Kilcoyne, J.; McCarron, P.; Twiner, M.J.; Nulty, C.; Wilkins, A.L.; Rise, F.; Quilliam, M.A.; Miles, C.O. Epimers of azaspiracids: Isolation, structural elucidation, relative LC-MS response, and in vitro toxicity of 37-epi-azaspiracid-1. Chem. Res. Toxicol. 2014, 27, 587-600. [CrossRef] [PubMed]

35. Kilcoyne, J.; McCoy, A.; Burrell, S.; Krock, B.; Tillmann, U. Effects of temperature, growth media, and photoperiod on growth and toxin production of Azadinium spinosum. Mar. Drugs 2019, 17, 489. [CrossRef]

36. Takai, A.; Murata, M.; Torigoe, K.; Isobe, M.; Mieskes, G.; Yasumoto, T. Inhibitory effect of okadaic acid derivatives on protein phosphatases. Biochem. J. 1992, 284, 539-544. [CrossRef]

37. Nagai, H.; Satake, M.; Yasumoto, T. Antimicrobial activities of polyether compounds of dinoflagellate origins. J. Appl. Phycol. 1990, 2, 305-308. [CrossRef]

38. Guillard, R.R.L.; Hargraves, P.E. Stichochrysis immobilis is a diatom, not a chrysophyte. Phycology 1993, 32, 234-236. [CrossRef]

Publisher's Note: MDPI stays neutral with regard to jurisdictional claims in published maps and institutional affiliations. 